\title{
BREVE TEORÍA Y PRÁCTICA DE LAS AUDIENCIAS PÚBLICAS EN EL PROCEDIMIENTO CONTENCIOSO INTERAMERICANO*
}

\author{
A Brief theory and Practice of the Public Hearings \\ in THe InTER-AMERICAN Litigation Process
}

\author{
Armando Salas Cruz ${ }^{*}$ \\ Suprema Corte de Justicia de México \\ armsalas@ucm.es / isonomiazul@hotmail.com
}

\begin{abstract}
RESUMEN: El objetivo del presente trabajo se dirige a revisar el principio de publicidad y su expansión en el procedimiento contencioso interamericano, según las preguntas básicas siguientes: ¿cuál podría ser la contribución para el procedimiento contencioso interamericano de la transmisión de las audiencias públicas en directo y su ulterior publicación en internet? y jesta práctica mejora el acercamiento de la Corte Interamericana a las comunidades nacionales que se encuentran bajo su competencia jurisdiccional? Sin embargo, adicionalmente a las respuestas encontradas sobre esos interrogantes a lo largo del análisis realizado, resulta relevante destacar, después de profundizar en el tema, la lógica contradictoria en la que se encuentra la práctica asumida por la Corte Interamericana tratándose de la realización de las audiencias de supervisión de cumplimiento de sus sentencias. Es decir, en este procedimiento, el principio prevaleciente es el de privacidad.

ABSTRACT: The object of this work is aimed at reviewing the principle of publicity and its expansion in the Inter-American litigation process, according to the following basic questions: What could be the contribution to the Inter-American litigation process transmission of public hearings live
\end{abstract}

* Trabajo recibido el 5 de octubre de 2016 y aprobado el 6 de junio de 2018.

Las abreviaturas utilizadas son las acostumbradas al uso de la doctrina: CADH o Convención Americana (Convención Americana sobre Derechos Humanos), CorteIDH o Corte Interamericana (Corte Interamericana de Derechos Humanos), CIDH o Comisión Interamericana (Comisión Interamericana de Derechos Humanos), OEA (Organización de los Estados Americanos), Estatuto CorteIDH o Estatuto (Estatuto de la Corte Interamericana de Derechos Humanos), Reglamento CorteIDH o Reglamento (Reglamento de la Corte Interamericana de Derechos Humanos), SCorteIDH (Sentencia de la Corte Interamericana de Derechos Humanos), RCorteIDH (Resolución de la Corte Interamericana de Derechos Humanos).

** Doctor en Derecho por la Universidad Complutense de Madrid, Maestro en Derecho por la Facultad de Derecho de la Universidad Nacional Autónoma de México y Diploma de Derecho Constitucional y Ciencia Política por el Centro de Estudios Políticos y Constitucionales (Madrid, España). Forma parte del Sistema Nacional de Investigadores del Conacyt. Agradezco a Yessica Esquivel Alonso y Mauro A. Rivera León la amabilidad que tuvieron de leer el borrador previo de este artículo y por los comentarios y observaciones que hicieron al mismo; cualquier imprecisión o error es de mi entera responsabilidad. 
and subsequent publication on the Internet? And this practice improves the approach of the InterAmerican Court to national communities under their jurisdiction? However, in addition to the found answers on these questions through the analysis, it is relevant to note, after deeper into the subject, the contradictory logic assumed by the Inter-American Court in the case of performing the hearings on monitoring compliance with its judgments. That is, in this process, privacy is a prevailing principle.

PALABRAS CLAVE: Audiencias públicas, Corte Interamericana de Derechos Humanos, principio de publicidad, transparencia judicial.

KEY WORDS: Public hearings, Inter-American Court of Human Rights, principle of publicity, judicial transparency.

\section{INTRODUCCIÓN}

La presencia de la jurisdicción interamericana cada vez es más visible en las realidades jurídicas nacionales de la región. Una herramienta de enorme utilidad para el acercamiento directo a las actividades de la Corte Interamericana como intérprete máximo de la Convención Americana se encuentra al alcance de los usuarios de internet: las audiencias públicas. Estas, conforme suceden los períodos de sesiones (ordinarios y extraordinarios) de dicho órgano jurisdiccional, se van integrando a una plataforma multimedia disponible para su consulta.

La pretensión de este trabajo es limitada. Se restringe a buscar los posibles beneficios de publicitar una parte del proceso contencioso interamericano. Para este fin, parto de la idea de que la utilización de los avances tecnológicos para el acercamiento de la sociedad a las actividades de los órganos judiciales favorece el escrutinio que aquella tiene sobre el proceso decisorio de estos.

Hasta hace poco, la Corte Interamericana decidió publicar los videos grabados de sus audiencias públicas a través de internet. También de realizar las transmisiones en directo. Según el propio tribunal, el 2011 marca el inicio de la transmisión en directo de las audiencias públicas como práctica permanente ${ }^{1}$. Tanto en su Informe anual 2011 como en el de 2012, se introdujo una sección específica ("Uso de nuevas tecnologías") que reporta el sentido de tal decisión:

"Con ello -afirma la CorteIDH- se busca hacer efectivo, en términos internacionales, el principio de publicidad, ya que las audiencias públicas deben ser accesibles no sólo para quienes tienen la oportunidad de estar físicamente presentes" y "[l]as transmisiones en vivo cumplen con el objetivo de difundir el trabajo en la Corte, darle una mayor publicidad a los hechos que aquejan a las víctimas y, sobre todo, a difundir el debate y análisis de distintos temas en la realidad interamericana de los

1 CorteIDH (2012), p. 64. 
derechos humanos, puesto que la discusión y el diálogo de estos tópicos favorecen la participación de ciudadanos comunes dentro del sistema"2.

Es decir, utilizar las herramientas proporcionadas por las nuevas tecnologías para difundir aquellas actividades que efectivamente le permite la reglamentación a la que está sujeta. Este cambio de actitud persigue principalmente el objetivo de dar a conocer al mayor número posible de habitantes del continente americano una fase esencial del proceso contencioso, la fase oral ${ }^{3}$.

Por último, es importante destacar que el presente texto se sustenta en gran medida en el análisis de un conjunto de audiencias públicas en procedimientos contenciosos celebradas por la Corte Interamericana en diferentes períodos ordinarios y extraordinarios de sesiones. Se trata de las audiencias públicas de los siguientes casos: Mohamed vs. Argentina; Vélez Restrepo y familiares vs. Colombia; Diaz Peña vs. Venezuela; Fernández Ortega vs. México; Nadege Dorzema vs. República Dominicana; Mendoza vs. Argentina; Artavia Murillo y otros (fecundación in vitro) vs. Costa Rica; Masacre de Santo Domingo vs. Colombia; Atala Riffo e hijas vs. Chile; Masacres de Río Negro vs. Guatemala; Gelman vs. Uruguay; Mémoli vs. Argentina; Quintana Coello y otros vs. Ecuador; Luna López vs. Honduras; Suárez Peralta vs. Ecuador; Ibsen Cárdenas e Ibsen Peña vs. Bolivia; Contreras y otros vs. El Salvador; García Lucero y otras vs. Chile; Camba Campos y otros vs. Ecuador, y, Norin Catrimán y otros (Lonkos, dirigentes y activistas del pueblo mapuche) vs. Chile. Por tanto, la mayoría de las reflexiones contenidas a lo largo del mismo se remiten a esta muestra que fue consultada por el autor en el período de julio de 2012 a junio de 2013.

La selección de tal conjunto de casos responde en principio a la diversidad del país contendiente, ya que existen significativas variaciones en la experiencia y calidad de la defensa jurídica realizada por las delegaciones de los Estados demandados, lo que de alguna forma incide en el desarrollo de la audiencia pública. Por otra parte, el período que ha sido seleccionado tiene que ver, en primer lugar, con la debida distancia entre el análisis realizado en esos años y los cambios que hasta nuestros días se han dado en la materia de interés. Así, en ese período ya se advierten las características fundamentales que actualmente

\footnotetext{
2 CorteIDH (2013), p. 92.

3 En este sentido, no hay que olvidar que el presupuesto ordinario de la Corte Interamericana es precario y limitado, motivo de queja recurrente en sus informes anuales. Véanse, por ejemplo, CorteIDH (2011), p. 19, CorteIDH (2012), p. 66 y CorteIDH (2013), p. 93.
} 
presentan las audiencias públicas celebradas hasta 2018. Esto hizo posible advertir la evolución en nuestro tópico. En segundo lugar, la muestra incluye casos relevantes en distintas materias de la jurisprudencia interamericana (masacres, desaparición forzada, discriminación por razón de género, destitución de jueces, pueblos indígenas), lo que permitió advertir elementos emergentes como -por ejemplo- el peso de los dictámenes periciales en temas complejos.

\section{EVOLUCIÓN DEL PRINCIPIO DE PUBLICIDAD}

\section{EN EL PROCEDIMIENTO CONTENCIOSO INTERAMERICANO}

A lo largo de los años de funcionamiento de la jurisdicción interamericana, el principio de publicidad ha sido una constante en la celebración de las audiencias en el procedimiento contencioso interamericano. De la revisión de los informes anuales de la Corte Interamericana, de 1980 al 20134, bien puede dividirse su evolución, para efectos de síntesis, en tres fases generales: 1) la instalación con fuerza de dicho principio como elemento rector del proceso; 2) los ajustes durante el camino para el mejoramiento de la práctica de las audiencias públicas, y, 3) consolidación, donde el uso de herramientas de las nuevas tecnologías contribuye en gran medida a la expansión de los alcances de este principio.

\section{ELEMENTO RECTOR DEL PROCESO}

Esta primera etapa puede ser identificada como el momento de adopción de una política de apertura, de máxima publicidad del procedimiento contencioso interamericano. Desde el inicio, al conocer y resolver los primeros casos contenciosos 5 , la Corte Interamericana entendió que la celebración de audiencias públicas estaba llamada a convertirse en uno de los principales mecanismos de los que disponía el tribunal para acercarse a las partes, tener contacto directo con ellas, entender sus posturas y escucharlas en el desahogo de las pruebas que le son presentadas. No podía erigirse en un tribunal alejado de las realidades nacionales. Asimismo, dicho principio también fue aplicado en los demás procedimientos, tanto en las opiniones consultivas como en las medidas provisionales. En estas

${ }^{4}$ Los respectivos informes anuales pueden ser consultados en la página web de la Corte Interamericana [última consulta: 25 de enero de 2016]. [http://www.corteidh.or.cr/index.php/es/al-dia/informes-anuales]. 5 SSCorteIDH contra Honduras: Velásquez Rodríguez (Fondo), de 29 de julio de 1988, párrs. 22 y 28, Fairén Garbi y Solís Corrales (Fondo), de 15 de marzo de 1989, párrs. 21 y 28, y Godínez Cruz (Fondo), de 20 de enero de 1989, párrs. 24 y 30. 
últimas, tuvo particular interés dada su naturaleza inherente de protección inmediata, y que podía conocer a través de las audiencias públicas la situación de gravedad de cada caso ${ }^{6}$.

Ahora bien, este afianzamiento de la publicidad como elemento rector del procedimiento contencioso interamericano además debe verse dentro del contexto en el que se insertaba la jurisdicción interamericana en la región, durante las décadas de los ochenta y noventa. En este sentido, debido a que el trabajo de la Corte Interamericana era precariamente seguido y sus resoluciones todavía no generaban el impacto que actualmente tienen, las audiencias públicas tenían una repercusión bastante imperceptible en el posicionamiento del trabajo de la Corte Interamericana de cara a la sociedad a la que se dirigía. Es decir, el principio de publicidad en esos momentos tiene que ser visto, por un lado, como parte del fortalecimiento de la Corte Interamericana como institución judicial internacional y, por el otro, como una garantía del debido proceso para las partes en controversia.

\section{AJUSTES DE LAS FORMAS: REDUCIR Y COMPACTAR}

A partir de la segunda mitad de la década de los noventa comienzan a percibirse ciertos problemas o dificultades con la celebración de las audiencias públicas, asociados directamente con la fragmentación propia del procedimiento contencioso en esos años. La Corte Interamericana acostumbraba a emitir una resolución en cada etapa que sucesivamente se iba celebrando, lo que también significaba que cada una de esas etapas se traducía en una audiencia pública, por lo que bien podían celebrarse hasta cuatro o cinco audiencias públicas (dependiendo del caso) durante todo el procedimiento. Así, había audiencia pública de excepciones preliminares, audiencia pública de pruebas, audiencia pública de fondo, audiencia pública de reparaciones y costas, y audiencia pública de comunicación de sentencia ${ }^{7}$.

\footnotetext{
6 Sobre la evolución jurisprudencial de este instituto, en sus distintas fases de tramitación (otorgamiento, modificación o extensión, y levantamiento), así como el objetivo buscado -mayor información sobre los asuntos- con la celebración de audiencias en este procedimiento, Corzo (2014).

7 Esta audiencia pública a la que se alude, de comunicación de sentencia, ya no existe actualmente, debido a las modificaciones que sufrió el Reglamento CorteIDH en junio de 2001. Hasta ese momento, el antiguo artículo 57.1 establecía que "Llegado el estado de sentencia, la Corte deliberará en privado, se tomará una decisión mediante votación, se aprobará la redacción de la sentencia y se fijará la fecha de la sesión pública en que se comunicará a las partes". Situación que, en perspectiva comparada, se sigue conservando en el
} 
Situación que produjo, como es lógico y según se desprende del acuerdo de la Corte Interamericana tomado en $1996^{8}$, problemas para completar el quórum necesario de jueces en la celebración de las audiencias públicas en ciertas fases del procedimiento. De igual forma, la Corte Interamericana menciona en dos diferentes momentos la búsqueda de soporte institucional para solventar los problemas originados por el crecimiento de la carga de trabajo9 ${ }^{9}$. Asimismo, la Corte Interamericana consideró conveniente reformar el entonces artículo 57.1 de su Reglamento con el objetivo de "[...] eliminar la práctica de realización de una audiencia pública para lectura y notificación de sentencias en virtud del principio de economía y celeridad procesal"10. Ejemplos que demuestran, en esos momentos, las dificultades para la Corte Interamericana del uso demasiado amplio de las audiencias públicas, tratando de buscar medidas para ajustarlas a sus recursos materiales y sustanciales.

sistema europeo, donde el artículo 6 del Convenio Europeo de Derechos Humanos exige, entre otras cosas, que "La sentencia debe ser pronunciada públicamente". Por su parte, el Reglamento del Tribunal Europeo de Derechos Humanos lo recoge de forma opcional en el artículo 77.2, al establecer que "La sentencia dictada por una Sala podrá ser leída en audiencia pública por el Presidente de la Sala o por otro Juez, por delegación. Los Agentes y representantes de las partes serán debidamente advertidos de la fecha de la audiencia de lectura. A falta de lectura en audiencia pública, la notificación prevista en el párrafo 3 del presente artículo equivaldrá al pronunciamiento de la sentencia”. Se ha tomado la traducción al castellano de las Rules of Court (edición de 1 de abril de 2011), de MorTe (2011), p. 297.

Por otra parte, si se toma en cuenta la posibilidad de que la Corte Interamericana podía emitir una resolución de interpretación de sentencia, cuando se dan las condiciones y es solicitada por alguna de las partes, también podía llegar a celebrarse otra audiencia pública con motivo de dicha etapa; lo que llegó a acontecer en aquellos momentos. Véanse CorteIDH (2001), p. 26, y RCorteIDH, Caso Cesti Hurtado vs. Perú, de 19 de noviembre de 1999 (interpretación de la sentencia de fondo), cons. 5 y res. 2.

8 Dicho acuerdo consistía en "Que la recepción de prueba testimonial y pericial en los procedimientos que se ventilan ante ella podrán verificarse con la presencia de uno o varios de sus miembros, en audiencia pública en la sede de la Corte o in situ", CorteIDH (1997), "Anexo XX". Y que tendrá pronta aplicación en el Caso Genie Lacayo, ibídem, "Anexo XXI".

9 Así, de la reunión sostenida con la CIDH en 1996, uno de los acuerdos a los que llegaron fue que "La Comisión contemplará la posibilidad de reformar su Reglamento para poder obtener prueba testimonial y pericial en forma contradictoria, con el propósito de que la Corte no tenga que recibirla en audiencias públicas y pueda fallar los casos con más celeridad". Supuesto que afortunadamente no aconteció, ya que, como se verá más adelante, en la actualidad es uno de los puntos fuertes de la etapa oral del procedimiento contencioso. Por otra parte, en una reunión que tuvo el pleno de la Corte Interamericana con el Secretario General de la OEA, el 4 de diciembre de 1996, dicho tribunal asentó que "En esta reunión se conversó sobre los problemas que tiene la Corte para cumplir con los mandatos convencionales, debido al volumen de trabajo que afronta y a los muchos testigos y peritos que debe escuchar en sus audiencias públicas", ambas citas, en CorteIDH (1997), capítulo II.G.

10 CorteIDH (1999), p. 20. 
Posteriormente, en 2001 y 2003, vendrán algunos ajustes en la práctica a partir de las reformas al Reglamento ${ }^{11}$. Los principales cambios estaban referidos a la participación procesal activa que se les concedía hasta esos momentos a las presuntas víctimas y sus representantes en el procedimiento contencioso (locus standi in judicio) ${ }^{12}$, sin embargo, en esa reestructuración, la práctica de la fase oral se redujo a una audiencia principal siguiendo el patrón de reducción en la emisión de sentencias por parte de la Corte Interamericana. Mientras el artículo 36.6, hasta el 31 de mayo de 2001, señalaba que la Corte Interamericana podía, si lo consideraba pertinente, fijar una audiencia especial para las excepciones preliminares, después de la cual tenía que decidir sobre las mismas; con la entrada en vigor de las modificaciones al Reglamento ( 1 de junio de 2001), esa disposición pasaba a habilitar a la Corte Interamericana para decidir de una sola vez sobre las excepciones preliminares y el fondo: "La Corte podrá resolver en una sola sentencia las excepciones preliminares y el fondo del caso, en función del principio de economía procesal".

Ahora bien, en materia de reparaciones, normativamente se siguió conservando la posibilidad para que la Corte Interamericana pudiera emitir una sentencia de reparaciones, conforme al artículo 56.1 del Reglamento. Pero en la práctica, y ya en la corriente de la economía procesal, su utilización disminuyó considerablemente. La decisión sobre las reparaciones se anudó a esa sola sentencia de excepciones preliminares y fondo.

Así, si en una sola sentencia podía decidirse sobre las excepciones preliminares, el fondo y las eventuales medidas de reparación, entonces también era adecuado verificarse esas cuestiones en una sola audiencia.

\section{Consolidación ACtual}

La tercera fase que identifico, y es en la que nos encontraríamos en la actualidad, es la consolidación de la forma compactada de una audiencia principal, que como se dijo anteriormente es una gran audiencia, donde se concentra lo que anteriormente se hacía en diversas audiencias (excepciones preliminares, desahogo de pruebas, fondo, y reparaciones y costas), por tanto, el principio de publicidad queda ahora concentrado en esta audiencia pública principal, que se

11 El Reglamento de 2000 fue aprobado por la Corte Interamericana en su XLIX período ordinario de sesiones, celebrado del 16 al 25 de noviembre de 2000. Las reformas entraron en vigor el 1 de junio de 2001.

12 Sobre la evolución del locus standi en la normativa interamericana, CANÇADO (2007b), p. 306. 
convierte en la etapa oral del procedimiento contencioso interamericano ${ }^{13}$. Esta concentración, o menor dispersión, ha favorecido el ahorro de recursos (desde el punto de vista financiero), pero también, y quizás sea lo de mayor relevancia, la cohesión del tribunal a la hora de conocer los asuntos.

Dicho esquema también fue favorable para que la Corte Interamericana pudiera celebrar sesiones extraordinarias fuera de su sede, donde el motor principal eran las audiencias públicas ${ }^{14}$. Con ello, impulsó con acierto el acercamiento e interés de la sociedad hacia su trabajo jurisdiccional.

Ahora bien, en esta fase de consolidación, la emergencia de las nuevas tecnologías de la información (principalmente internet) como herramientas a disposición de la Corte Interamericana para aumentar la resonancia de la celebración de las audiencias públicas y, por tanto, también el alcance del principio de publicidad en el procedimiento contencioso, ha facilitado el acceso de los usuarios a una de las etapas de mayor relevancia del proceso (la oral), a su conocimiento y desarrollo de forma directa. Panorama que, sin duda, ha contribuido a fortalecer las relaciones del Tribunal con las diversas comunidades de la región a las que dirige sus sentencias.

\section{SigNIFICADO Y ALGUNAS FUNCIONES DE LAS AUDIENCIAS PÚBLICAS}

\section{ELEMENTOS SIGNIFICATIVOS}

\section{A. Publicidad del proceso}

La publicidad del proceso es un mandato que se encuentra en varias disposiciones de la normativa reglamentaria del sistema interamericano de derechos humanos. En principio, la celebración de las audiencias es pública, aunque se le otorga la facultad a la Corte Interamericana para cuando así lo decida poder efectuarlas de forma privada. Debido a su relevancia, quizás sea conveniente citar textualmente los preceptos relativos. El artículo 24.1 Estatuto CorteIDH establece lo siguiente: "Las audiencias serán públicas, a menos que la Corte, en casos excepcionales, decida lo contrario". Por su parte, el artículo 15.1 Reglamento CorteIDH es el que introduce el término "privadas": "La Corte celebrará

13 García (2006), p. 153.

14 Sobre la repercusión, desarrollo y algunos de los beneficios que ha traído consigo la celebración de audiencias públicas (tanto de casos contenciosos como de medidas provisionales) fuera de la sede de la Corte Interamericana, SaAvedra y PACHECo (2009), pp. 37-73. 
audiencias cuando lo estime pertinente. Éstas serán públicas, salvo cuando el Tribunal considere oportuno que sean privadas".

En términos generales, esa celebración pública se cumpliría en el momento de no impedirse el acceso, a los medios de comunicación social, personas interesadas y terceros, al lugar donde se haya fijado previamente la verificación y desahogo de los actos procesales particulares en los casos programados ${ }^{15}$. En este sentido, la Corte Interamericana positivamente ha ido más allá de esta obligación, al ofrecer al público que se encuentra fuera de la sala de audiencias la posibilidad de presenciar en tiempo real (cuando las sesiones son transmitidas en directo) y, más importante aún, indirectamente, en cualquier momento, de forma virtual, al poderse consultar los videos que son grabados de las audiencias públicas celebradas, mismos que son cargados y archivados en una plataforma multimedia ${ }^{16}$.

Aunado a lo anterior, debe tenerse en cuenta la obligación que tiene la Corte Interamericana de hacer constar en grabaciones de audio las audiencias y deliberaciones que celebre. Se trata del artículo 15.4 del Reglamento, el cual establece que "[e]l desarrollo de las audiencias y deliberaciones de la Corte constará en grabaciones de audio". Dicho dispositivo se limita a expresar el mandato, sin embargo no dice el fin que se persigue con dichas constancias. Es obvio que en perspectiva procesal esto sirve de soporte documental para posteriores reflexiones de los jueces y los funcionarios (abogados) de la Corte Interamericana en la consulta de datos específicos expresados en el desarrollo de las audiencias. Respecto de las deliberaciones, el mismo artículo 15, pero en su apartado 2, introduce un impedimento expreso para su difusión, en tanto "[l]a Corte deliberará en privado y sus deliberaciones permanecerán secretas", pero para efectos de la publicidad del desarrollo de las audiencias al parecer no existiría algún impedimento, más allá de las posibilidades materiales de que disponga la Corte Interamericana.

Por supuesto, como cabe advertir, lo anterior no incluye la grabación en medios audiovisuales. Sin embargo, esto no sería una limitante para la Corte Interamericana de poder grabar las audiencias con el fin de hacerlas públicas, pues

15 Con referencia al sistema español, O’CALlaghan (1999), p. 277, entiende que “[e]l principio de publicidad del proceso se manifiesta esencialmente en la realización a puerta abierta del juicio oral en el proceso penal y de la práctica de las pruebas y vistas orales en el proceso civil. Los terceros, 'el público' pueden presenciar tales actos directa y personalmente", cursivas del original.

16 Cfr., CorteIDH (2013), p. 92. 
así se lo permite el artículo 32.1.c del Reglamento, que establece lo siguiente: "[1]a Corte hará público [...] el desarrollo de las audiencias, salvo las de carácter privado, a través de los medios que se considere adecuados”. Entonces, según lo anterior, habría dos tipos de grabaciones que hacen constar las audiencias celebradas, por un lado se encontrarían las grabaciones obligatorias de audio para su uso al interior de la Corte Interamericana, que no necesariamente tendrían carácter público y, por el otro, aquellas otras grabaciones que tienen el objetivo específico de hacer público el desarrollo de las audiencias, donde tienen cabida distintos soportes de difusión (como puede ser internet).

\section{B. Transparencia de las actividades}

Sin dejar de advertir que el vocablo "transparencia" es un concepto amplio y maleable, según el terreno donde sea colocado, la idea mínima de su significado remite a una característica o cualidad de un ente determinado que permite apreciar, a simple vista, su interior o la pureza de su composición.

En el espacio jurídico, el concepto de transparencia se encuentra mayormente asociado al derecho de acceso a la información ${ }^{17}$. En este sentido, el concepto de transparencia no es autónomo sino se remite a una función específica que desempeña en el entramado de ese derecho. De hecho, la transparencia es definida como una "garantía de efectividad" del derecho de la información, es decir, forma parte de éste y, por tanto, su alcance depende también del contenido de tal derecho ${ }^{18}$.

No obstante lo anterior, la noción de transparencia utilizada en este trabajo es una transparencia referida al interior del trabajo judicial, transparencia que pretende mostrar con la mayor cercanía posible el funcionamiento y las actividades de los poderes del Estado, incluyendo por supuesto a los tribunales. Conforme con esta idea, la transparencia en el ámbito judicial quiere mostrar el funcionamiento de los órganos judiciales y su actividad básica, esto es, la de dictar sentencias.

17 Guerrero (2008), p. 12, señala que "La transparencia es un atributo o cualidad que nos permite tener más información clara y precisa sobre algo o alguien, lo que aumenta nuestras capacidades de comprensión, vigilancia y comunicación".

18 Según Villanueva (2009), p. 1311, “[...] la transparencia es una garantía normativa e institucional no jurisdiccional para hacer efectivo el derecho de acceso a la información pública. En tanto la transparencia es una garantía, no un derecho sustantivo, hace las veces de una herramienta o instrumento legal para alcanzar los propósitos que justifican la existencia del derecho de acceso a la información pública”. 
Sobre el particular, en la doctrina jurisprudencial de la Corte Interamericana referida a la libertad de expresión y la formación de una opinión pública sólida en cuestiones de interés público, se puede alcanzar a percibir el impacto de la idea de transparencia en el fortalecimiento del control que tiene la sociedad de las instituciones públicas. Lo que también cabría extender a las autoridades internacionales. En este sentido, la Corte Interamericana en el Caso Ricardo Canese ${ }^{19}$, siguiendo la jurisprudencia del Tribunal de Estrasburgo, estimó lo siguiente:

"El control democrático, por parte de la sociedad a través de la opinión pública, fomenta la transparencia de las actividades estatales y promueve la responsabilidad de los funcionarios sobre su gestión pública, razón por la cual debe existir un mayor margen de tolerancia frente a afirmaciones y apreciaciones vertidas en el curso de los debates políticos o sobre cuestiones de interés público"20.

Si bien es cierto que las consideraciones citadas se encuentran enmarcadas en la línea del ejercicio de la libertad de expresión ${ }^{21}$, los términos utilizados de "control democrático a través de la opinión pública", "transparencia de las actividades estatales", "responsabilidad de los funcionarios sobre su gestión pública" y "cuestiones de interés público" adquieren sentido en el presente trabajo, principalmente a partir de este último concepto, donde se ubica el accionar de la Corte Interamericana -una cuestión de interés público-, órgano con responsabilidades no solo institucionales, ante la organización regional a la que pertenece, sino principalmente ante la comunidad a la que se dirigen sus sentencias, por ello transparentar sus actividades ayuda o contribuye a que esa comunidad se

19 SCorteIDH, Ricardo Canese vs. Uruguay (fondo, reparaciones y costas), de 31 de agosto de 2004.

20 Ibídem, párr. 97. En un caso previo, la Corte Interamericana utilizó una expresión distinta en la última parte: "[...] debe existir un margen reducido a cualquier restricción del debate político o del debate sobre cuestiones de interés público", SCorteIDH, Herrera Ulloa vs. Costa Rica (excepciones preliminares, fondo, reparaciones y costas), de 2 de julio de 2004, párr. 127. Afirmación que también aparece en las consideraciones de la sentencia Kimel vs. Argentina (fondo, reparaciones y costas), de 2 de mayo de 2008, párr. 87: "[e]l control democrático a través de la opinión pública fomenta la transparencia de las actividades estatales y promueve la responsabilidad de los funcionarios sobre su gestión pública”.

21 En el caso en cuestión, el señor Ricardo Canese, candidato en las elecciones presidenciales del Paraguay de 1993 y en el contexto de la campaña electoral, cuestionó a otro candidato sus vínculos con una empresa constructora vinculada al régimen militar del dictador Alfredo Stroessner. Al hacerse públicas sus declaraciones en medios impresos paraguayos, algunos socios de la empresa aludida se sintieron agraviados y entablaron proceso penal en contra de Canese, resultando condenado por el delito de difamación. 
forme una opinión pública al respecto, y de esa forma escrutar y controlar de mejor forma a los jueces interamericanos ${ }^{22}$.

De igual forma, la Carta Democrática Interamericana, misma que ha sido bien recibida por la CorteIDH en la interpretación de la Convención Americana y doctrinalmente puede estimarse como la opinio iuris de la región en la materia ${ }^{23}$, en su artículo 4 estipula la "transparencia de las actividades estatales" como uno de los componentes fundamentales del ejercicio de la democracia. En este sentido, queda reforzada la obligación para la CorteIDH de transparentar sus actividades, siendo un órgano de defensa de los derechos humanos y, por tanto, también de la democracia.

Según lo anterior, la Corte Interamericana es el garante de la transparencia del procedimiento contencioso.

\section{Diálogo y legitimación}

Llegar a la instancia de la Corte Interamericana no es sencillo, significa recorrer un largo camino -en ocasiones tortuoso y no libre de obstáculos- para quienes se han manifestado víctimas de violaciones de derechos humanos. Presentarse ante los miembros de dicho Tribunal, en sesión oficial, ser escuchados y de alguna forma dialogar directamente con ellos, respondiendo a los cuestionamientos y compartiendo de viva voz su dolor, muestra la importancia del diálogo y el debate suscitado en las audiencias públicas. Posiblemente este propósito de escuchar a las partes se cumpliría de igual forma si las audiencias fueran privadas, a puerta cerrada, pero sin duda restringiría los efectos que pudieran producirse de cara a la comunidad, que también está interesada en conocer los asuntos que se discuten en sede interamericana.

Si se me permite la imagen, las audiencias públicas son un "puente" que permite trasladar el sentir de determinados sectores o colectivos de las comunidades nacionales ante los espectadores de toda la región ${ }^{24}$. Pero obviando el carácter

\footnotetext{
22 A propósito de la publicidad de los juicios, NAVArRo (2011), p. 83, sostiene una idea similar: "La publicidad de los actos de la Administración de Justicia es, por tanto, una garantía para la sociedad democrática ya que esa transparencia fortalece la confianza en el funcionamiento del Poder Judicial y aumenta la responsabilidad de los órganos de la Administración de Justicia que se sienten vigilados por la opinión pública”.

23 Sobre el valor de la unanimidad en la aprobación de ciertas resoluciones de órganos internacionales y su configuración como opinio iuris general o colectiva en temas específicos, PASTOR (2012), p. 152.

${ }^{24}$ En especial este carácter puede observarse en las audiencias públicas de los casos Nadege Dorzema; Masacres de Río Negro, y Norín Catrimán y otros (Lonkos, dirigentes y activistas del pueblo mapuche).
} 
lúdico e informativo de las audiencias públicas, estas ayudan a legitimar la función del juez interamericano ante los principales receptores de sus actuaciones. Es decir, un tribunal abierto al escrutinio de la sociedad favorece su inserción en el medio que actúa y su autoridad también se fortalece, a través de sus actuaciones y decisiones. Por el contrario, un tribunal hermético y ensimismado, sin contacto directo con la sociedad, tendrá menores posibilidades de encontrar el respaldo necesario para validar su actuación judicial.

Bogdandy y Venzke entienden que dentro del procedimiento judicial se aloja una dosis importante de capacidad para legitimar democráticamente las sentencias ${ }^{25}$. Esto puede generarse a través de dos características:

(1) "la justificación de las decisiones con respecto a los participantes en el proceso. Las partes en disputa están interesadas en la manera en que el caso es manejado y el tribunal debe lidiar con los argumentos que ellas presentan. Este tratamiento cooperativo de los temas en disputa no está solamente confinado a cuestiones de hecho o elementos probatorios sino que también se extiende a cuestiones de derecho" y (2) "ubicar la decisión judicial dentro del contexto general de justificación de la autoridad pública. La abierta discusión de intereses y las posiciones contrapuestas es parte de la base social de la democracia que alimenta el público democrático así como los procesos de integración social. Las sentencias de los tribunales son parte de esto y albergan un potencial democrático sólo si están inmersas en discursos normativos" 26 .

Así, ciertos procedimientos (elementos procesales), como las audiencias públicas, la intervención de terceros, y los amici curiae, incentivan la publicidad, la transparencia y las oportunidades de participación, ayudan a establecer una mejor comunicación con la sociedad, y permiten que esta última conozca suficientemente la forma en que actúan y deciden los tribunales internacionales. Según dichos autores, espacios que tradicionalmente se rigen por la regla de la confidencialidad (la Organización Mundial del Comercio y el Centro Internacional de Arreglo de Diferencias relativas a Inversiones) están abriéndose a la práctica de procedimientos orales públicos y la publicación de sus decisiones ${ }^{27}$.

25 Bogdandy y VenzKe (2013), p. 109.

26 Ibídem, p. 110.

27 Ibídem, pp. 110 y ss. 


\section{Algunas tesis SOBRe SU UTILIDAD O FUnCIONES}

\section{A. Como ejercicio de concordancia entre lo actuado y lo resuelto}

En términos generales, la audiencia pública interamericana puede estructurarse en tres etapas: la presentación del caso, el desahogo de las pruebas ${ }^{28}$, y los alegatos finales de las partes y observaciones finales de la Comisión Interamericana.

En la primera, el Presidente de la Corte Interamericana abre formalmente la audiencia ${ }^{29}$ y la delegación de la Comisión Interamericana hace la presentación del caso, indicando principalmente los antecedentes materiales y formales de la controversia, los motivos que la llevaron a presentar el caso ante la Corte Interamericana y, por último, la relevancia o contribución de la resolución para los estándares interamericanos de derechos humanos. Cabe destacar que la integración de dicha delegación dependerá del tema de derechos humanos en controversia o el país demandado y, en cierta medida, de la relevancia del caso. Sin embargo, esta aparente variabilidad en la conformación, tiene un eje de permanencia en el equipo de abogados especialistas encargados de litigar los casos ante la Corte. Así, normalmente, la delegación de la Comisión Interamericana estará encabezada por alguno de los Comisionados y dos funcionarios de la Secretaría Ejecutiva: la Secretaria Ejecutiva Adjunta y un abogado especialista. Ahora bien, según lo dicho, cuando se trata de algún asunto temático en particular, como la libertad de expresión, la delegación la puede encabezar la Relatoría Especial para la Libertad de Expresión ${ }^{30}$.

Las dos últimas etapas propiamente son el momento de interacción de los jueces con las partes. Estas son escuchadas y, por otro lado, pueden ser interrogadas. Según la descripción que hace Fix-Zamudio:

"La presentación de los medios de convicción ofrecidos por las partes y admitidos por la Corte Interamericana, se realiza por medio de una o varias audiencias en las cuales se rinden las declaraciones de los testigos y se presentan oralmente los dictámenes de los peritos, todos los cuales pueden ser interrogados por ambas partes de

\footnotetext{
28 Con excepción de las pruebas documentales, todas las demás pruebas deben desahogarse en audiencia pública, cfr. Fix-Zamudio (2003), p. 208. Este particular peso puesto en las audiencias públicas no puede menos que mostrar su relevancia para el proceso contencioso interamericano.

29 En algunos casos, en el supuesto de excusa del Presidente para conocer de algún asunto en particular, el Vicepresidente asume la conducción de la audiencia pública, según lo establecido en el artículo 5 Reglamento CorteIDH.

30 Véanse, por ejemplo, las audiencias de los casos Vélez Restrepo y familiares y Mémoli.
} 
manera sucesiva, y una vez terminado el interrogatorio, que como hemos señalado tiene carácter contradictorio, los jueces de la Corte Interamericana pueden, a su vez, formular preguntas y repreguntas a los mencionados peritos y testigos [...]"31.

En efecto, las declaraciones de los testigos y las presentaciones de los peritos son el núcleo central de la etapa oral. Por ello se otorga decidida atención a los interrogatorios, siendo el momento que los jueces tienen a través de la dialéctica de la sesión (las preguntas y repreguntas) para ir definiendo sus razonamientos, que aún no son definitivos, respecto del caso en concreto. En este sentido, también cabe destacar el papel relevante que desempeñan los informes periciales ${ }^{32}$, en tanto los jueces no pueden ser especialistas en todos y cada uno de los ordenamientos jurídicos internos que integran el sistema de la Convención Americana, o ante la emergencia de un tópico o tema específico de los derechos humanos que requiere de la participación o ayuda de otras disciplinas científicas o técnicas ajenas al derecho ${ }^{33}$, y que solo pueden ser solventadas por profesionales capacitados. Es este el fin que se persigue con la participación de peritos en el proceso interamericano, allegar a los jueces de conocimientos específicos y especializados que les permitan tomar una mejor decisión, proporcionarles elementos fundados de índole técnica o científica a sus razonamientos.

La tercera etapa, y última, es lo que se puede decir llanamente como las conclusiones de la sesión, presentadas respectivamente por las partes y la Comisión Interamericana. Dichas conclusiones lógicamente están condicionadas por el desarrollo de la etapa anterior, es decir, de la evolución que haya acontecido en los interrogatorios de los testigos y los peritos, de las manifestaciones que se hayan hecho. Asimismo, también es la parte donde la Corte Interamericana, conforme con su práctica constante, solicita se hagan observaciones orales sobre las posibles medidas de reparación que entenderían las víctimas deben ser las aplicadas en el caso en cuestión. Es decir, la Corte Interamericana entiende que es necesario darles voz a los afectados, a través de sus representantes, respecto de sus pretensiones y necesidades que estiman deben ser reparadas por la vulneración de sus derechos.

31 Fix-Zamudio (2003), p. 208.

32 Sobre el tema, Solano (1998), pp. 1451-1469.

33 A modo de ejemplo, resulta paradigmática la audiencia del Caso Artavia Murillo y otros (fecundación in vitro), donde la ciencia médica tuvo notable protagonismo. Asimismo, aunque en menor medida, el debate sobre el funcionamiento y efectos de ciertos explosivos, con un perito militar experto en armamento, marcó la audiencia del Caso Masacre de Santo Domingo. 
En esa estructura de etapas sucesivas los intervinientes en la audiencia pública interamericana se pueden clasificar en tres grandes grupos: a) las partes, esto es, por un lado, los representantes de la presunta víctima y, por el otro, la defensa del Estado demandado; b) los coadyuvantes del proceso: testigos, peritos o amicus curiae, y c) la Comisión Interamericana. Cada uno de tales grupos tiene un interés específico al acudir a la audiencia pública, más allá de presentar sus argumentos, declaraciones, alegatos, observaciones o conclusiones ante los jueces integrantes de la Corte Interamericana.

Las partes, por supuesto, están interesadas en comprobar y fortalecer sus respectivas posiciones, pero un tema fundamental para el equipo de representación de la presunta víctima es aprovechar la presencia de los jueces para sensibilizarlos acerca de sus necesidades y pretensiones en cuanto a las posibles reparaciones en el caso concreto; la defensa del Estado demandado, en cambio, busca evitar o disminuir los costos que conlleva una condena internacional.

Los coadyuvantes del proceso, aunque es más dispar su objetivo conforme a la posición que guardan en el proceso, proporcionan información relevante y deben hacerlo de la mejor manera. La Comisión Interamericana, por su parte, tiene deberes concretos e institucionales para con el desarrollo y extensión de los estándares de protección de los derechos humanos en la región.

Dentro del primer grupo, los pueblos y comunidades indígenas son uno de los colectivos destacados en el uso de las audiencias públicas. Tanto en Masacres de Rio Negro (pueblo maya) como en Norín Catrimán y otros (Lonkos, dirigentes $y$ activistas del pueblo mapuche), los testimonios reflejan y confirman las circunstancias a las que se enfrentan cotidianamente, y que luego coinciden con el contenido de las sentencias ${ }^{34}$. A la Corte Interamericana le interesa documentar y contextualizar el origen y los factores de exclusión social que favorecen la violación de los derechos de los pueblos y comunidades indígenas.

En suma, parte considerable del conocimiento teórico adquirido a través de los textos sobre el funcionamiento de la Corte Interamericana puede ser confrontado (validar, confirmar o negar) con la vista de las audiencias públicas, eso es exactamente lo que permiten las transmisiones en directo y los videos grabados y publicados en Internet de las audiencias públicas, un acercamiento directo. Este tipo de acercamiento, a su vez, genera una sociedad mejor informada de la forma en que se desarrolla el proceso interamericano.

34 Masacres de Río Negro, párrs. 55-106, y Norín Catrimán y otros (Lonkos, dirigentes y activistas del pueblo mapuche), párrs. 73-152. 


\section{B. Función reparadora}

Aquí propiamente no se trata de las medidas de reparación que la Corte Interamericana dicta cuando en algún caso específico encuentra la violación de alguno o varios de los derechos reconocidos en la Convención Americana, sino del efecto o impacto que pueden producir las audiencias públicas precisamente en la experiencia de aquellas personas que fueron reconocidas como víctimas. Las audiencias públicas, según alude Martín (2008) ${ }^{35}$, son "un espacio reparador" principalmente por el carácter de escucha, diálogo e interacción que se establece entre los peticionarios y los jueces interamericanos.

Esto se vuelve más claro en el supuesto de inexistencia de la audiencia pública durante el procedimiento contencioso. En 2006, la Corte Interamericana decidió en diversos casos no celebrar audiencia pública ${ }^{36}$, sin embargo, en dos de ellos resulta más difícil saber el motivo de la decisión de la Corte de no convocarlas, en tanto en la sentencia sólo se refleja el resultado y no las razones de esa decisión ${ }^{37}$. Pero es en los votos particulares del juez Cançado Trindade donde asoma de mejor forma el debate interno sobre este tema en particular. En el Caso Servellón García y otros, dicho juez manifestó:

"La Corte, ante los términos del reconocimiento de responsabilidad del Estado, se equivocó en su deliberación apresurada de dejar de convocar una audiencia pública sobre este importante caso. La audiencia pública que no hubo, hubiera ciertamente enriquecido la presente Sentencia, en tres aspectos: a) hubiera enriquecido el expediente e instrucción del caso (sobre todo ante la actitud positiva de colaboración procesal asumida por el Estado): b) hubiera aplicado a cabalidad e[1] principio del contradictorio en cuanto al contexto del presente caso, y c) hubiera servido de satisfacción (como forma de reparación) a los familiares de las víctimas. Pero el

35 El citado autor efectúa un interesante estudio (y bastante amplio, donde se incluye la fase de las audiencias públicas) del sistema interamericano de derechos humanos a partir de los testimonios (207 entrevistas) de los principales actores que interactúan en él (peticionarios y familiares, abogados defensores y asociaciones civiles de defensa de derechos humanos, especialistas, agentes estatales, abogados de la Comisión y la Corte Interamericana, comisionados de la $\mathrm{CIDH}$ y jueces de la CorteIDH) donde reconstruye el itinerario que debe seguirse cuando se activa alguna demanda o queja, principalmente desde la mirada de la reparación integral de la víctima, pues su enfoque es el de un especialista en psicología forense.

36 SSCorteIDH, Comunidad indigena Sawhoyamaxa vs. Paraguay (fondo, reparaciones y costas), de 29 de marzo de 2006, párr. 17, Servellón García y otros vs. Honduras, de 21 de septiembre de 2006, párr. 18, y Goiburú y otros vs. Paraguay (fondo, reparaciones y costas), de 22 de septiembre de 2006, párr. 18.

37 Martín (2008), p. 199, señala que "En el caso Sawhoyamaxa, la Corte no llamó a audiencia por su similitud con el de Yakye Axa, de la misma etnia, y juzgado previamente". 
actual afán -que no comparto, y al cual me opongo-, de productividad de la Corte (acompañada de decisiones inevitablemente aceleradas), el actual afán insensato de decidir la mayor cantidad posible de casos en tiempo récord, la privó de elementos que pudieran haber enriquecido esta Sentencia" 38 .

Si se extrae del contexto en que fueron señalados - por Cançado Trindadelos elementos de enriquecimiento que significaba la audiencia pública para el caso concreto, y de esta forma poder generalizarlos, entonces puede observarse que siguen conservando su aplicación para cualquier asunto discutido en el procedimiento contencioso, es decir, las audiencias públicas enriquecen al mismo procedimiento y a las sentencias, en términos de mayores elementos para el expediente, del principio de "contradictorio" (que tan relevante es para el procedimiento interamericano), y de forma de reparación o satisfacción para los peticionarios.

\section{Efecto educativo}

De la discusión pública de temas de significativa relevancia y en muchas de las ocasiones divergentes para las sociedades de la región (como la reproducción asistida, las masacres, las amenazas a la democracia o la discriminación por cuestiones de género), surge también el carácter educativo de cara a la sociedad. Es decir, se presenta a la sociedad una discusión especializada, con la presentación de posiciones, pensamientos y argumentos igualmente válidos de las partes y los intervinientes, que en un cierto sentido pueden verse como la síntesis de un debate más amplio en los diversos sectores de la sociedad. Este efecto educativo de las audiencias públicas, sin embargo, es limitado y su impacto puede variar dependiendo del asunto o tema en controversia.

Así, por ejemplo, en casos difíciles -como lo acontecido en el caso de Costa Rica frente a la fecundación in vitro- este efecto puede tener mayor repercusión, debido a la mayor difusión y atención puesta por los medios de comunicación social, y donde la propia naturaleza compleja de definir ciertos aspectos técnicos o científicos (como las técnicas de reproducción asistida y sus posibles efectos en

\footnotetext{
38 Voto razonado, párr. 3, cursiva del original. En el voto razonado a la sentencia del Caso Goiburú y otros será aún más crítico con la mayoría de la Corte, pero en esencia vuelven a aparecer los mismos elementos, y los factores de la celeridad procesal ("productividad" de la Corte) y el reconocimiento de responsabilidad por parte del Estado parecen ser los motivos fundamentales para que deje de convocarse la audiencia pública.
} 
la protección jurídica del derecho a la vida desde el momento de la concepción del ser humano) permite confrontar posturas divergentes entre especialistas.

Ahora bien, será limitado en el sentido de que las audiencias públicas interamericanas históricamente han funcionado de forma cerrada a la participación pública, es decir, no pueden presentarse libremente o por invitación personas ajenas al proceso (especialistas, representantes de los sectores sociales afectados, organizaciones de la sociedad civil, etcétera) para presentar sus razones e ideas que puedan contribuir a la mejor solución del caso ${ }^{39}$. Sin embargo, no puede descartarse que el siguiente escalón en el fortalecimiento de las audiencias públicas interamericanas se encuentre en la apertura hacia la participación pública y activa de las personas interesadas en el debate de los derechos humanos, cuestiones que siguen teniendo el carácter de interés público ${ }^{40}$.

Por otra parte, también habrá que tomar en consideración la escasa atención que la mayoría de la ciudadanía dedica a la revisión y análisis de las sentencias y resoluciones de la Corte Interamericana. En este sentido, los tribunales supremos nacionales al dirigir su atención directa hacia alguna resolución interamericana en particular, contribuyen indirectamente a la atención que puedan poner los ciudadanos en esa resolución. En México, por ejemplo, a partir de la discusión de la sentencia del Caso Radilla Pacheco ${ }^{41}$ en el Pleno de la Suprema Corte de Justicia de México y que dio origen al relevante expediente Varios 912/201042,

39 Es cierto que en el proceso interamericano existe otro tipo de instrumentos que tienen esta función, como los amicus curiae. Sobre el particular, el artículo 2.3 Reglamento señala que "la expresión 'amicus curiae' significa la persona o institución ajena al litigio y al proceso que presenta a la Corte razonamientos en torno a los hechos contenidos en el sometimiento del caso o formula consideraciones jurídicas sobre la materia del proceso, a través de un documento o de un alegato en audiencia”. De conformidad con lo anterior, no puede descartarse que se haya presentado algún alegato oral proveniente de amicus curiae en la larga trayectoria de celebración de audiencias públicas en el procedimiento contencioso, sin embargo, debido a lo limitado (en este punto específico) de la muestra utilizada para este trabajo no puede confirmarse tal extremo. No obstante lo anterior, en la práctica actual, los amicus curiae no son expresados en audiencia pública.

40 Referente a esta idea se han tenido en cuenta los resultados positivos que se han presentado en el caso de las audiencias públicas convocadas -inéditas hasta esos momentos- por los respectivos altos tribunales de Argentina, Brasil y México, para la resolución de casos relevantes. Sobre las audiencias públicas convocadas por el Supremo Tribunal Federal de Brasil, Lopes y Limberger (2012) y respecto de la Corte Suprema de Argentina, LoRenzetTi (2014), p. 349.

41 SCorteIDH, Radilla Pacheco vs. Estados Unidos Mexicanos (Excepciones preliminares, fondo, reparaciones y costas), de 23 de noviembre de 2009.

42 Suprema Corte de Justicia de la Nación, Expediente varios 489/2010, de 7 de septiembre de 2010 y Expediente varios 912/2010, de 14 de julio de 2011. 
la sociedad en general y en especial los sectores judicial, político, académico, comenzó a poner una mayor atención en el impacto de las decisiones de la Corte Interamericana en el orden jurídico mexicano.

\section{Como objeto de estudio}

Quien por distintos motivos ha tenido la oportunidad de acercarse a la literatura especializada existente sobre el sistema interamericano de derechos humanos, en general, y la Corte Interamericana, en específico, sabrá que se ha multiplicado considerablemente en los últimos años. Dos posibles razones pueden explicarlo, la primera tiene que ver con el papel de la Corte Interamericana en la región, es decir, su función y legitimidad, y la segunda se relaciona con los efectos jurídicos y políticos de sus decisiones jurisdiccionales en los ordenamientos nacionales ${ }^{43}$, teniendo consecuentemente, a mi juicio, evidente repercusión en el interés social y académico.

Por ello, para todos aquellos que se encuentran dedicados a las labores de docencia e investigación, y que tienen como objeto de estudio la jurisdicción interamericana, la transmisión en directo y los videos de las audiencias públicas resultan una herramienta útil e indispensable para el acercamiento personal, sin intermediarios, al desarrollo y evolución de una etapa esencial del proceso interamericano, acercarse a sus claves, significados y consecuencias, pero no sólo esto, que ya de por sí es sustancial, sino también a las actitudes de las partes intervinientes y los jueces. Esto último, precisamente, resulta de enorme relevancia para identificar prima facie el pensamiento de cada uno de los jueces interamericanos.

\section{E. Perfil, aunque limitado, de los miembros del tribunal}

Dada la naturaleza de la integración de la Corte Interamericana, al ser un tribunal internacional, resultan más evidentes las diferencias de formación y pensamiento jurídico entre sus miembros, quienes proceden de diversas realidades sociales y culturales. Aunque, en oposición a este planteamiento, cabe el reparo de que esa distancia entre realidades no sea tan amplia si se mira o compara con

43 Sobre el tema, un panorama general y sintético lo ofrece GARCÍA-SAYÁn (2008), pp. 15 y ss., también debe consultarse GarCía-SAYÁn (2005), pp. 323-384; para los posibles efectos políticos, Vio (2010), pp. 111-136. De forma más amplia, Corzo et al. (2013). 
la lupa de las semejanzas existentes entre los países de habla hispana; en cambio, donde sí pueden aumentar considerablemente las diferencias es respecto de la situación que presentan los países integrantes de la zona del Caribe (Caribbean Community o Caricom), de habla inglesa y que responden a una tradición jurídica de common law ${ }^{44}$.

Este acercamiento al perfil de los jueces interamericanos de ninguna manera puede ser profundo o decisivo, sino simplemente aproximativo. Por lo menos, ayudaría a ir tejiendo una idea acabada del pensamiento de algún juez en específico y saber prospectivamente hacia dónde se dirigirá su posición ante algún caso en concreto, según sus intervenciones y manifestaciones en audiencias públicas previas ${ }^{45}$.

\section{F. Acercamiento a las estrategias de litigio utilizadas por las partes}

Por último, la publicación de los videos de las audiencias públicas celebradas por la Corte Interamericana también cobra importancia sustancial para todas aquellas personas, organizaciones o instituciones, que se encuentran en la fase de diseño o preparando sus estrategias de litigio en el nivel interamericano, ante la certeza de que serán llamados en audiencia pública ante los jueces de la Corte Interamericana.

Es cierto que existen manuales que explican cabalmente el proceso interamericano ${ }^{46}$, sin embargo, estos tienen un natural carácter conciso y su acercamiento a los detalles de ciertos elementos (como las audiencias públicas) es limitado. Así,

44 Hasta antes de la renovación de 2013, entre los integrantes de la Corte Interamericana se encontraba la entonces jueza Margarette May Macaulay, originaria de Jamaica. Por otro lado, en la composición actual solo encontramos a un juez cuyo idioma materno no es el español, Roberto F. Caldas, de origen brasileño.

45 En esta dirección, otro recurso de importante utilidad para conocer más de cerca el pensamiento jurídico de alguno de los jueces interamericanos (en particular, sus razonamientos y los criterios aplicados a casos concretos o frente a temas particulares de los derechos humanos) son los votos particulares que en muchas ocasiones acompañan a las sentencias del órgano judicial interamericano. Estos, en términos generales, son opiniones motivadas que le permiten al juez desarrollar y justificar algún punto de acuerdo o, principalmente, de desacuerdo con el sentido final o términos en que quedó redactada la sentencia. Pueden clasificarse de varias formas, pero la categoría más común es la del voto disidente, es decir, aquel que expresa desacuerdo ante parte o la totalidad de la sentencia. Sobre este tema, Gros (1987-1989), pp. 23-43; respecto de la tipología de los votos, Rodríguez (2009), pp. 28-29. Asimismo, existen las recopilaciones de los votos de destacados jueces de la Corte Interamericana que han terminado su período lectivo: GarCía Ramírez (2005), hay edición posterior (2014), y CANÇADO (2007a).

46 Entre otros, Faúndez (2004), en específico el apartado "La fase oral", pp. 708 y ss., y PasQualucci (2003), en especial el apartado "Oral Proceedings", pp. 193 y ss. 
frente a la ventaja de presenciar de forma personal el desarrollo de una audiencia pública, el texto solo funciona como marco referencial. Siguiendo esta idea, lo más conveniente es acudir directamente a dicho recurso, lo que permite establecer una base precisa para determinar la eficacia en la utilización de los tiempos de que disponen las partes, evitar las repeticiones inútiles de argumentos y, como ya mencionamos antes, establecer un perfil aproximado de los miembros que integran la Corte Interamericana.

Por otra parte, siguiendo la muestra de estudio ${ }^{47}$, cabe destacar que los testimonios son altamente valorados por los jueces interamericanos, en tanto muchos de los demandantes no fueron oídos en sede nacional por los órganos judiciales competentes. Es decir, la sede interamericana se convierte en la única instancia donde los peticionarios pueden exponer su peregrinar $y$, en consecuencia, la función del abogado, en esos momentos, debe dirigirse a maximizar o minimizar -según el caso- sus efectos. En principio, este punto suele ser el de mayor interés para los operadores jurídicos que se desenvuelven en el litigio interamericano ${ }^{48}$.

\section{LAS AUDIENCIAS EN OTROS PROCEDIMIENTOS}

El panorama de la celebración de audiencias en la jurisdicción interamericana no se encuentra circunscrito solamente -como ya se había señalado con anterioridad- a la fase oral del procedimiento contencioso. También pueden encontrarse tanto antes como después de dicho procedimiento. Si bien es cierto que su Reglamento le otorga a la Corte Interamericana la posibilidad de celebrarlas "cuando lo estime pertinente", la práctica del tribunal indica algunos sectores específicos donde se observa su conveniencia. Así, tratándose del otorgamiento de medidas provisionales, esto es, antes de la mencionada fase oral del procedimiento contencioso, a partir principalmente de la década anterior, algunos jueces comenzaron a manifestarse a favor de la necesidad y conveniencia de celebrar

\footnotetext{
47 Véase el contenido de esa muestra en la introducción del presente trabajo.

48 Cierta conexión entre el litigio interamericano y las audiencias públicas puede percibirse en el trabajo de Cavallaro y Brewer (2008), pp. 85-99. Más allá de las dos posturas en disputa de la forma técnica -descrita por los autores- para llevar casos de derechos económicos, sociales y culturales a los órganos del sistema interamericano, principalmente ante la Corte Interamericana, los abogados encargados del litigio interamericano deben estar atentos a las audiencias públicas de la Corte Interamericana. Es aquí donde encuentro tal conexión, pues en estas hay una fuente primordial de información para la preparación de la estrategia en las sucesivas fases del proceso interamericano, en especial la oral.
} 
audiencias públicas en esta materia ${ }^{49}$. Por otra parte, al encontrarse integrada la función supervisora a la competencia jurisdiccional, las últimas reformas al Reglamento han introducido la posibilidad de que en la fase de supervisión de cumplimiento - después del procedimiento contencioso- la Corte Interamericana pueda celebrar audiencias. Sin embargo, en esta fase ocurre una situación peculiar que viene a contradecir el principio de publicidad en los procedimientos celebrados por ese tribunal.

\section{ANTES DEL PROCEDIMIENTO CONTENCIOSO:}

\section{MEDIDAS PROVISIONALES}

En el caso de las medidas provisionales de la Corte Interamericana ${ }^{50}$, la celebración de audiencias es una práctica constante que se viene realizando desde $1990^{51}$, no de forma sistemática pero se mantiene en la evolución de este procedimiento como una herramienta útil para la Corte Interamericana cuando requiere de información indispensable de las partes para la emisión de la resolución correspondiente. Actualmente, sin embargo, la práctica de las audiencias en materia de medidas provisionales es más intensa. En cuanto al principio de publicidad, aquí es importante destacar que las audiencias privadas son más frecuentes, en comparación con la práctica en el procedimiento contencioso, aunque siguen comportándose como una excepción. De hecho, hasta 2006, las estadísticas de la Corte Interamericana reportan la celebración exclusivamente de audiencia públicas tratándose de medidas provisionales ${ }^{52}$.

La Corte Interamericana describe de forma general el desarrollo de este tipo de audiencias:

49 En particular, voto conjunto de los jueces A. A. Cançado Trindade y M. E. Ventura Robles a la RCorteIDH, solicitud de medidas provisionales presentada por la Comisión Interamericana de Derechos Humanos respecto de los Estados Unidos Mexicanos, Caso Jorge Castañeda Gutman, de 25 de noviembre de 2005.

\footnotetext{
50 Corzo (2014).

51 De la revisión general de los informes anuales que presenta la Corte Interamericana a la Asamblea General de la OEA, en el informe correspondiente a 1990 se refiere la que puede considerarse como la primera audiencia pública celebrada en materia de medidas provisionales, en el Caso Bustíos-Rojas, el 7 de agosto de 1990. Al respecto, véase CorteIDH (1991), p. 14 y RCorteIDH, Medidas provisionales solicitadas por la Comisión Interamericana de Derechos Humanos respecto del Perú, Caso Bustíos-Rojas, de 8 de agosto de 1990.

52 Véase la tabla estadística "Audiencias públicas en medidas provisionales", CorteIDH (2007), p. 99.
} 
"En una audiencia sobre medidas provisionales, que suelen durar alrededor de dos horas, los representantes de los beneficiarios y la Comisión Interamericana tienen la oportunidad de evidenciar, de ser el caso, la subsistencia de las situaciones que determinaron la adopción de medidas provisionales; mientras que el Estado debe presentar información sobre las medidas adoptadas con la finalidad de superar esas situaciones de extrema gravedad, urgencia e irreparabilidad del daño y, en el mejor de los casos, demostrar que tales circunstancias han dejado de verificarse en los hechos. En dicha audiencia los solicitantes de las medidas provisionales inician la presentación de sus alegatos respecto a la configuración de las tres referidas condiciones, seguidos por la Comisión Interamericana o los representantes de los beneficiarios, según sea el caso, finalizando el Estado con la presentación de sus correspondientes observaciones. Tanto los representantes y la Comisión, así como el Estado tienen la opción de réplica y dúplica, respectivamente. Finalmente, los jueces tienen la posibilidad de formular cuestionamientos a los participantes en la audiencia" 53 .

De ese objetivo inicial señalado para celebrar una audiencia en este procedimiento y la postura activa adoptada por el tribunal en esta materia, cabe entender que, en ocasiones, la información documental y escrita se vuelve insuficiente para los jueces, quienes tienen que apreciar y, en consecuencia, actualizar las condiciones indispensables para la adopción de medidas provisionales (extrema gravedad, urgencia e irreparabilidad del daño), según los hechos del caso. Por lo que la audiencia, sea pública o privada, cumple una función de relevancia en las decisiones del tribunal relativas al otorgamiento, mantenimiento y supervisión del cumplimiento de las medidas provisionales, así como en su levantamiento, aunque no siempre su celebración sea fija y tenga carácter adicional ${ }^{54}$.

\section{DeSPUÉS DEL PROCEDIMIENTO CONTENCIOSO: SUPERVISIÓN}

DE CUMPLIMIENTO DE SENTENCIAS

Ahora bien, las audiencias también pueden ser convocadas en la fase de supervisión de cumplimiento de las decisiones de la Corte Interamericana. Según Ferrer Mac-Gregor es una práctica reciente que comenzó en 2007, habiéndose

\footnotetext{
53 CorteIDH (2011), p. 4.

$54 \mathrm{Al}$ respecto, la Corte Interamericana indica que "[...] a partir de los informes remitidos por los Estados y de las correspondientes observaciones enviadas por los representantes de los beneficiarios y de la Comisión Interamericana, la Corte evalúa la pertinencia de convocar a los involucrados a una audiencia en la que se deberá presentar el estado de las medidas adoptadas [...]”, Ídem.
} 
celebrado 77 audiencias hasta el 201355, y utilizada de forma sistemática en la actualidad ${ }^{56}$. Sin embargo, esa posibilidad de la Corte Interamericana de celebrar audiencias con fines de supervisar el cumplimiento de sus decisiones se ha limitado a que sean audiencias privadas. Con lo cual iría en dirección contraria respecto de la práctica de las audiencias públicas en el proceso contencioso interamericano. Esto llevaría a reflexionar sobre la justificación de que la regla esté invertida en la función supervisora que tiene la Corte Interamericana. ¿Por qué las audiencias son privadas y no públicas, cuando las exigencias de transparencia y publicidad serían en principio las mismas que en la fase oral del procedimiento contencioso interamericano? Las justificaciones o razones por supuesto vienen de necesidades prácticas: 1) ahorro de recursos económicos y técnicos, 2) utilización de espacios e infraestructura menos exigente para la celebración de la audiencia, 3) facilidad en la organización del evento, 4) menor tiempo de duración de la audiencia, entre otras, pero no se compadecen con los objetivos sustanciales de su mayor cercanía con la población a la que se dirigen y la mejor construcción de la legitimidad de sus decisiones.

La Corte Interamericana, con relación a la celebración de audiencias en la fase de supervisión de cumplimiento de sus decisiones, señaló que "Ninguna norma de la Convención ni del Estatuto y el Reglamento de la Corte le exige a ésta que celebre audiencias públicas para resolver sobre el fondo de los casos y disponer las reparaciones, por lo que se desprende que tampoco es necesaria la celebración de audiencias para considerar el cumplimiento de las sentencias, salvo si el Tribunal lo estima indispensable" 57.

El sentido de la afirmación citada es el cuestionamiento que hizo Panamá de la falta de celebración de audiencias en el procedimiento de supervisión de cumplimiento del fallo en el Caso Baena Ricardo. Sin embargo, el deslizamiento del adjetivo "públicas" lleva a confusión, ya que esto soslaya algunas indicaciones del Estatuto y el Reglamento, esencialmente del principio de publicidad en la celebración de las audiencias en la jurisdicción interamericana. En mi concepto, dicho principio opera también en la celebración de las audiencias en la fase de supervisión de cumplimiento de las sentencias.

\footnotetext{
55 Cfr. Voto concurrente del juez Eduardo Ferrer en la Resolución de supervisión de cumplimiento de sentencia, Caso Gelman vs. Uruguay, de 20 de marzo de 2013, párr. 2.

56 Cfr. García Ramírez y Zangui (2012), p. 469.

57 SCorteIDH, Baena Ricardo y otros vs. Panamá (Competencia), de 28 de noviembre de 2003, párr. 106.
} 
El artículo 15 del Reglamento es el que habilita de forma general a la Corte Interamericana para celebrar audiencias, sin limitar su celebración a una fase en específico de los distintos supuestos en los que se puede encontrar el conocimiento de algún caso (por ejemplo, medidas provisionales, excepciones preliminares, fondo y reparaciones en el procedimiento contencioso o, precisamente, supervisión de cumplimiento de sus decisiones). Así, el artículo 15.1 del Reglamento establece que "[l]a Corte celebrará audiencias cuando lo estime pertinente. Éstas serán públicas, salvo cuando el Tribunal considere oportuno que sean privadas”. Por lo que si bien es cierto que no hay una exigencia de celebración de audiencias, y la Corte Interamericana tiene la facultad de decidir la necesidad de celebrarlas, también es cierto que sí aparece una exigencia en la forma o el tipo de audiencia que debe celebrarse, esto es, de forma pública, y solo en casos excepcionales, pueden ser privadas. Lo que vendría a ser confirmado por el señalamiento que hace el artículo 24 del Estatuto, en tanto el principio es la publicidad y no la privacidad de las audiencias. Por su parte, existe un dispositivo particularizado de las audiencias en la función de supervisión de cumplimiento de sus decisiones que es el utilizado recientemente por la Corte Interamericana ${ }^{58}$, a partir de que fuera introducido con las últimas reformas del Reglamento de la Corte Interamericana en $2009^{59}$.

Esto trajo, como consecuencia, el incremento en la celebración de audiencias en esta fase, cambiando esa primera reticencia de la Corte Interamericana expresada en su momento en el procedimiento de supervisión de la sentencia del Caso Baena Ricardo a destacarse su importancia para dicha etapa: "Las audiencias han contribuido a lograr la efectividad de las decisiones de la Corte IDH. No se trata de una mediación del fallo, sino de una actividad dinámica que permite contar con información reciente para que los jueces puedan realizar una adecuada valoración sobre el cumplimiento del fallo por el Estado concernido, a la vez de propiciar espacios de diálogo constructivo favoreciendo el entendimiento entre las partes y lograr el debido cumplimiento

\footnotetext{
58 Es el artículo 69.3 Reglamento CorteIDH, el cual señala que "Cuando lo considere pertinente, el Tribunal podrá convocar al Estado y a los representantes de las víctimas a una audiencia para supervisar el cumplimiento de sus decisiones, y en ésta escuchará el parecer de la Comisión".

59 En un primer momento, en la reforma de principios de 2009 se adicionó un nuevo artículo (el 63) que venía a recoger la práctica de la Corte Interamericana en materia de supervisión del cumplimiento de sus decisiones, para quedar, posteriormente, en la reforma de finales de 2009 y que entraría en vigor el 1 de enero de 2010, en el actual artículo 69.
} 
de lo decidido en la sentencia, particularmente sobre las diversas formas de reparación para las víctimas" 60 .

Según lo anterior, el principio elemental de la celebración de audiencias en esta fase se sigue manteniendo con el que rige en las audiencias celebradas en el proceso contencioso y en la ocasional fase previa de medidas provisionales, que no es otro que el de escuchar a las partes. Sin embargo, su función y utilidad están conectadas con el contexto de la fase en el cual se proyectan aquellas audiencias, por lo que ya no es el desahogo de las pruebas que requieren unas reglas rígidas -como en la fase contenciosa- sino el de ser un "espacio de diálogo" que permita a la Corte Interamericana cumplir con su función de supervisión. Y esto tiene cierta lógica, ya que en la audiencia de supervisión de cumplimiento de sentencia no están en discusión las medidas de reparación, sino la forma en que se deben de cumplir, por ello para la Corte Interamericana resulta indispensable contar con la interacción oral con las partes para emitir las correspondientes resoluciones que el caso específico requiera y, ulteriormente, responder a su obligación de informar a la Asamblea General de la OEA.

Pero como se ha visto, la práctica en esta fase no puede desprenderse de la lectura conjunta de los artículos referidos, menos aún de la exigencia de publicidad en la celebración de audiencias. En este sentido, la práctica que hasta el momento ha mantenido la Corte Interamericana en la fase de supervisión de cumplimiento de sus decisiones se encuentra invertida; cuando decide celebrar audiencias, lo hace de forma privada, siendo la otra opción -la pública- la excepción.

Esto también ignora la práctica de publicidad que la Corte Interamericana ha mantenido en la fase del procedimiento contencioso. Desde que resolvió sus primeros casos ${ }^{61}$, la celebración de audiencias públicas (tanto en la resolución de las excepciones preliminares, como en el fondo y las reparaciones) se ha convertido en pieza indispensable, quizás esencial, de la función jurisdiccional de este tribunal.

\footnotetext{
60 Voto concurrente del juez Eduardo Ferrer en la Resolución de supervisión de cumplimiento de sentencia, Caso Gelman vs. Uruguay, de 20 de marzo de 2013, párr. 2. También puede consultarse en Ferrer (2013), pp. 607-638. En términos similares del objetivo perseguido con la celebración de audiencias en esta etapa, GARCía RAMíreZ y ZANGHI (2012), p. 469, expresan que sirven “[...] para apreciar avances, estancamientos o retrocesos en el cumplimiento de las sentencias, y proveer decisiones conducentes a la ejecución debida (artículo 69 Reglamento), así como desahogar los planteamientos de quienes fueron partes en el proceso y ahora son participantes en la ejecución de la condena".
}

61 SCorteIDH, Velásquez Rodríguez vs. Honduras (Fondo), de 29 de julio de 1988, párrs. 22 y 28. 


\section{CONSIDERACIONES FinAlES}

Las audiencias públicas han estado presentes desde los primeros casos contenciosos conocidos por la Corte Interamericana y su celebración son una pieza indispensable y distintiva de sus principales funciones jurídicas. El principio de publicidad es el que rige la celebración de las audiencias en todos los procedimientos que lleva a cabo, sean de medidas provisionales, contenciosas, consultivas y, en definitiva, de supervisión de cumplimiento de sus decisiones.

En este sentido, según la evolución del principio de publicidad, que es el que rige las audiencias en los distintos procedimientos seguidos por la Corte, puede decirse actualmente que este principio es el eje rector de las actuaciones de dicho Tribunal, teniendo soporte tanto en la normativa interamericana como en su práctica. Sin embargo, existen diferencias considerables en la aplicación de tal principio según el procedimiento específico.

Mientras en el procedimiento contencioso el principio de publicidad es una regla casi absoluta -ya que históricamente ha habido ocasiones en que la audiencia pública se ha dejado de celebrar por motivos de economía procesal-y se ha llegado a la publicación en medios electrónicos, es decir, resulta imprescindible para garantizar un juicio imparcial y de cara no solo a las partes sino a todas las comunidades de la región.

Por su parte, en el procedimiento de supervisión de sentencias la aplicación de la regla de publicidad es muy relativa, hasta el grado de encontrarse, en estos momentos, invertida la lógica, es decir, el principio de privacidad es el que prevalece en la celebración de audiencias durante este procedimiento.

La importancia de las audiencias públicas en el procedimiento contencioso radica en que son una fuente de legitimidad y una ventana de escrutinio de las actividades jurisdiccionales de la Corte Interamericana. Más allá de algunas de las atribuciones didácticas que se han señalado en este trabajo, es a través de las audiencias como se sustancia la fase oral, siendo la audiencia pública del procedimiento contencioso la de mayor relevancia, ya que es allí donde se desahoga la mayoría de las pruebas del caso concreto, a la vista de todos.

\section{BibliografíA CITADA}

Von Bogdandy, Armin y Venzke, Ingo (2013). “¿En nombre de quién? Un estudio sobre la autoridad pública de los tribunales internacionales y su justificación democrática”, en Ferrer Mac-Gregor, Eduardo y Herrera García, 
Alfonso (coords.), Diálogo jurisprudencial en derechos humanos entre tribunales constitucionales y cortes internacionales (Valencia, Tirant lo Blanch-IIDCCorteIDH-UNAM), pp. 83-129.

Cançado Trindade, Antonio A. (2007a). Derecho internacional de los derechos humanos: esencia y trascendencia. Votos en la Corte Interamericana de Derechos Humanos, 1991-2006 (México, Porrúa-Universidad Iberoamericana).

Cançado Trindade, Antonio A. (2007b). "La persona humana como sujeto del derecho internacional: avances de su capacidad jurídica internacional en la primera década del siglo XXI", en Revista IIDH (No 46), pp. 273-329.

Cavallaro, James L. y Brewer, Stephanie E. (2008). "La función del litigio interamericano en la promoción de la justicia social”, en Sur. Revista Internacional de Derechos Humanos (No 8), pp. 85-99.

Corzo Sosa, Edgar (2014). Medidas provisionales de la Corte Interamericana de Derechos Humanos (México, Tirant lo Blanch).

Corzo Sosa, Edgar; Carmona Tinoco, Jorge U. y SaAvedra Alessandri, Pablo (coords.) (2013). Impacto de las sentencias de la Corte Interamericana de Derechos Humanos (México, Tirant lo Blanch-IIDC-CorteIDH).

Faúndez Ledesma, Héctor (2004). El sistema interamericano de protección de los derechos humanos. Aspectos institucionales y procesales, $3^{\text {a }}$ ed. (San José de Costa Rica, Instituto Interamericano de Derechos Humanos).

Ferrer Mac-Gregor, Eduardo (2013). "Eficacia de la sentencia interamericana y la cosa juzgada internacional: vinculación directa hacia las partes (res judicata) e indirecta hacia los Estados parte de la convención americana (res interpretata) (Sobre el cumplimiento del Caso Gelman vs. Uruguay)", en Anuario de Derecho Constitucional Latinoamericano, pp. 607-638.

Fix-Zamudio, Héctor (2003). "Orden y valoración de las pruebas en la función contenciosa de la Corte Interamericana de Derechos Humanos", en A.A.V.V., Memoria del Seminario El sistema interamericano de protección de los derechos humanos en el umbral del siglo XXI, San José de Costa Rica, 23 y 24 de noviembre de 1999, 2a ed. (San José de Costa Rica, Corte Interamericana de Derechos Humanos), Tomo I, pp. 197-215.

García Ramírez, Sergio (2005). Temas de la jurisprudencia interamericana sobre derechos humanos: votos particulares (Guadalajara, Instituto Tecnológico y de Estudios Superiores de Occidente-Universidad Iberoamericana-Universidad de Guanajuato). 
García Ramírez, Sergio (2006). "La protección de derechos y libertades en el sistema jurisdiccional interamericano. El amparo internacional”, en La jurisdicción interamericana de derechos humanos (Estudios) (México, Comisión de Derechos Humanos del Distrito Federal-CorteIDH), pp. 115-159.

García Ramírez, Sergio (2014). Votos particulares en la Corte Interamericana de Derechos Humanos (México, Comisión Nacional de los Derechos Humanos). García Ramírez, Sergio y Zanghi, Claudio (2012). "Las jurisdicciones regionales de derechos humanos y las reparaciones y efectos de las sentencias", en García Roca, Javier et al. (eds.), El diálogo entre los sistemas europeo y americano de derechos humanos (Cizur Menor, Civitas-Thomson Reuters), pp. 423-491.

García-Sayán, Diego (2008). "Sistema interamericano de derechos humanos: efectos de las decisiones de la CIDH”, en Diálogo Político (No 4), pp. 11-35.

GarCíA-SAYÁn, Diego (2005). "Una viva interacción: Corte Interamericana y tribunales internos”, en VV.AA., La Corte Interamericana de Derechos Humanos. Un cuarto de siglo: 1979-2004 (San José de Costa Rica, Corte Interamericana de Derechos Humanos), pp. 323-384.

Gros EsPiell, Héctor (1987-1989). "Opiniones disidentes y separadas en la Corte Interamericana de Derechos Humanos”, en Anuario Argentino de Derecho Internacional (núm. III), pp. 23-43.

Guerrero Gutiérrez, Eduardo (2008). La transparencia (México, Nostra Ediciones).

Lopes Saldanha, Jânia M. y Limberger, Têmis (2012). "La dimensión constitucional del proceso brasileño: la apertura democrática del Supremo Tribunal Federal brasileño por medio de las audiencias públicas y la concretización de los derechos fundamentales sociales", en Revista General de Derecho Constitucional (núm. 14), pp. 1-17.

Lorenzetti, Ricardo (2014), "Las audiencias públicas y la Corte Suprema”, en Gargarella, Roberto (comp.), Por una justicia dialógica, (Buenos Aires, Siglo Veintiuno Editores), pp. 345-354.

Martín Beristain, Carlos (2008). Diálogos sobre la reparación: experiencias en el sistema interamericano de derechos humanos (San José de Costa Rica, Instituto Interamericano de Derechos Humanos), T. 1.

Morte Gómez, Carmen (2011). Cómo presentar una demanda ante el Tribunal Europeo de Derechos Humanos (Valencia, Tirant lo Blanch).

Navarro Marchante, Vicente J. (2011). El derecho a la información audiovisual de los juicios (Madrid, Centro de Estudios Políticos y Constitucionales). 
O'Callaghan, Xavier (1999). "Audiencias públicas y cobertura informativa”, en Poder Judicial (núm. especial 17), pp. 273-281.

Pasqualucci, Jo M. (2003). The Practice and Procedure of the Inter-American Court of Human Rights (Cambridge, Cambridge University Press).

Rodríguez Rescia, Víctor (2009). Las sentencias de la Corte Interamericana de Derechos Humanos. Guía modelo para su lectura y análisis (San José de Costa Rica, Instituto Interamericano de Derechos Humanos).

Saavedra Alessandri, Pablo y Pacheco Arias, Gabriela (2009). "Las sesiones 'itinerantes' de la Corte Interamericana de Derechos Humanos: un largo y fecundo caminar por América”, en García Ramírez, Sergio y Castañeda Hernández, Mireya (coords.), Recepción nacional del derecho internacional de los derechos humanos y admisión de la competencia contenciosa de la Corte Interamericana (México, UNAM-Instituto de Investigaciones Jurídicas), pp. 37-73.

Solano Monge, María A. (1998). "La prueba pericial ante la Corte Interamericana de Derechos Humanos", en VV.AA., Liber amicorum: Héctor Fix-Zamudio (San José de Costa Rica, CorteIDH-Unión Europea), Vol. II, pp. 1451-1469. Villanueva, Ernesto (2009). “Transparencia”, en Carbonell, Miguel (coord.), Diccionario de derecho constitucional, $3^{\text {a }}$ ed. (México, Porrúa, UNAM-Instituto de Investigaciones Jurídicas), T. II, pp. 1308-1312.

Vio Grossi, Eduardo (2010). "Sentencias de la Corte IDH: efectos políticos de sus fallos”, en Diálogo Político (núm. 4), pp. 111-136.

\section{DOCUMENTOS CITADOS}

Corte Interamericana de Derechos Humanos (2013), Informe anual 2012 (San José de Costa Rica).

Corte Interamericana de Derechos Humanos (2012), Informe anual 2011 (San José de Costa Rica).

Corte Interamericana de Derechos Humanos (2011), Informe anual 2010 (San José de Costa Rica).

Corte Interamericana de Derechos Humanos (2001), Informe anual de la Corte Interamericana de Derechos Humanos 2000 (San José de Costa Rica).

Corte Interamericana de Derechos Humanos (2007), Informe Anual de la Corte Interamericana de Derechos Humanos 2006 (San José de Costa Rica). 
Corte Interamericana de Derechos Humanos (1999), Informe Anual de la Corte Interamericana de Derechos Humanos 1998 (San José de Costa Rica). Corte Interamericana de Derechos Humanos (1997), Informe anual de la Corte Interamericana de Derechos Humanos 1996 (San José de Costa Rica). Corte Interamericana de Derechos Humanos (1991), Informe Anual de la Corte Interamericana de Derechos Humanos 1990 (San José de Costa Rica).

\section{NORMAS JURÍDICAS CITADAS}

Convención Americana sobre Derechos Humanos.

Convenio Europeo de Derechos Humanos.

Estatuto de la Corte Interamericana de Derechos Humanos.

Reglamento de la Corte Interamericana de Derechos Humanos.

Reglamento del Tribunal Europeo de Derechos Humanos (Rules of Court).

\section{JURISPRUDENCIA CITADA}

Baena Ricardo y otros vs. Panamá (2003). Corte Interamericana de Derechos Humanos Resolución 28 de noviembre de 2003 (Competencia).

Bustios-Rojas (1990). Corte Interamericana de Derechos Humanos 8 de agosto de 1990 (Resolución Medidas provisionales solicitadas por la Comisión Interamericana de Derechos Humanos respecto del Perú).

Cesti Hurtado vs. Perú (1999). Corte Interamericana de Derechos Humanos 19 de noviembre de 1999 (Resolución de interpretación de la sentencia de fondo). Expediente varios 489/2010 (2010). Suprema Corte de Justicia de la Nación 7 de septiembre de 2010.

Expediente varios 912/2010 (2011). Suprema Corte de Justicia de la Nación 14 de julio de 2011.

Gelman vs. Uruguay (2013). Corte Interamericana de Derechos Humanos 20 de marzo de 2013 (Resolución de supervisión de cumplimiento de sentencia). Jorge Castañeda Gutman vs. México (2005). Corte Interamericana de Derechos Humanos 25 de noviembre de 2005 (Resolución solicitud de medidas provisionales presentada por la Comisión Interamericana de Derechos Humanos respecto de los Estados Unidos Mexicanos, caso Jorge Castañeda Gutman). 
Radilla Pacheco vs. Estados Unidos Mexicanos (2009). Corte Interamericana de Derechos Humanos 23 de noviembre de 2009 (Excepciones preliminares, fondo, reparaciones y costas).

Ricardo Canese vs. Uruguay (2004). Corte Interamericana de Derechos Humanos 31 de agosto de 2004 (Fondo, reparaciones y costas).

Velásquez Rodríguez vs. Honduras (1998). Corte Interamericana de Derechos Humanos 29 de julio de 1988 (Fondo).

\section{AUdiENCIAS PÚBLICAS CONSULTADAS}

Artavia Murillo y otros (fecundación in vitro) vs. Costa Rica.

Atala Riffo e hijas vs. Chile.

Camba Campos y otros vs. Ecuador.

Contreras y otros vs. El Salvador.

Díaz Peña vs. Venezuela.

Fernández Ortega vs. México.

García Lucero y otras vs. Chile.

Gelman vs. Uruguay.

Ibsen Cárdenas e Ibsen Peña vs. Bolivia.

Luna López vs. Honduras.

Masacre de Santo Domingo vs. Colombia.

Masacres de Río Negro vs. Guatemala.

Mémoli vs. Argentina.

Mendoza vs. Argentina.

Mohamed vs. Argentina.

Nadege Dorzema vs. República Dominicana.

Norín Catrimán y otros (Lonkos, dirigentes y activistas del pueblo mapuche) vs. Chile.

Quintana Coello y otros vs. Ecuador.

Suárez Peralta vs. Ecuador.

Vélez Restrepo y familiares vs. Colombia. 